\title{
Mapping of a new autosomal dominant nonsyndromic hearing loss locus (DFNA30) to chromosome 15q25-26
}

\author{
Massimo Mangino ${ }^{1}$, Elisabetta Flex ${ }^{1}$, Francesca Capon ${ }^{2}$, Federica Sangiuolo ${ }^{2}$, \\ Edoardo Carraro ${ }^{3}$, Francesca Gualandi ${ }^{4}$, Manuela Mazzoli ${ }^{3}$, Alessandro Martini ${ }^{3}$, \\ Giuseppe Novelli ${ }^{*, 2}$ and Bruno Dallapiccola ${ }^{1}$
}

${ }^{1}$ CSS Mendel Institute, IRCCS, Rome, Italy; ${ }^{2}$ Department of Biopathology and Diagnostic Imaging, Tor Vergata University of Rome, Rome, Italy; ${ }^{3}$ ENT Department, University of Ferrara, Ferrara, Italy; ${ }^{4}$ Department of Genetics, University of Ferrara, Ferrara, Italy

Hearing impairment is the most common inherited human sensory defect. Nonsyndromic Hearing Impairment (NSHI) is the most genetically heterogeneous trait known. Over 70 loci have been mapped and a total of 19 genes have been identified. We report here a novel locus (DFNA 30) for autosomal dominant NSHI that we mapped to chromosome 15q25-26 in an Italian four-generation family. The haplotype analysis has identified a critical interval of $18 \mathrm{~cm}$ between markers D15S151 and D15S130. This region does not overlap with DFNB16 locus but partially coincides with the otosclerosis (OTS) locus. Localisation of the locus DFNA30 is a first step towards the identification of the gene. European Journal of Human Genetics (2001) 9, 667-671.

Keywords: DFNA30; genetic linkage; nonsyndromic hearing impairment; 15q25-26

\section{Introduction}

Hearing impairment is the most common inherited human sensory defect, affecting one in 2000 births. ${ }^{1}$ Clinically, hearing impairment may be associated with other disorders (syndromic) or it may be the only symptom (nonsyndromic). ${ }^{2}$ Nonsyndromic hearing impairment (NSHI) is the most genetically heterogeneous trait known. ${ }^{3}$ Over 70 loci have been mapped and a total of 19 genes have been identified. ${ }^{4}$ This extreme genetic heterogeneity is due to the structural and functional complexity of the inner ear. ${ }^{5} \mathrm{We}$ have investigated a four-generation family segregating an autosomal dominant NSHI and localised the gene responsible for this defect to chromosome 15q25-26 by genome wide scanning.
*Correspondence: G Novelli, Cattedra di Genetica Umana, Università di Roma Tor Vergata, Facoltà di Medicina e Chirurgia, Ed. E-Nord P.terra, Via di Tor Vergata 135, 00133 Roma, Italy. E-mail: novell@med.uniroma2.it Received 16 May 2001; revised 29 June 2001; accepted 3 July 2001

\section{Materials and methods \\ Subjects}

We analysed an Italian four-generation family in which NSHI is transmitted as an autosomal dominant trait (Figure 1). All participating family members underwent a clinical examination and thus clinical status was determined unequivocally. Environmental factors were eliminated as the cause of hearing loss in all affected family members. The age of onset of hearing loss ranged from 10 to 40 years. In all patients the hearing loss was bilateral and symmetric involving first high frequencies $(>2000 \mathrm{~Hz}$ ) and then progressing to middle frequencies $(500-2000 \mathrm{~Hz})$, resulting in a characteristic sloping audiogram. Audiometrical characteristics are rather similar for all the members of the family. The study was approved by the institutional review boards of the Tor Vergata (Rome) and Ferrara Universities and appropriate informed consent was obtained for all subjects.

\section{Genotyping}

Genome scanning was performed using 358 microsatellite markers loci from ABI PRISM ${ }^{\mathrm{TM}}$ Linkage Mapping Set at a distance of approximately $10 \mathrm{cM}$. PCR was performed using $50 \mathrm{ng}$ of DNA in a $15 \mu \mathrm{l}$ reaction mixture containing $1.5 \mu \mathrm{l}$ 


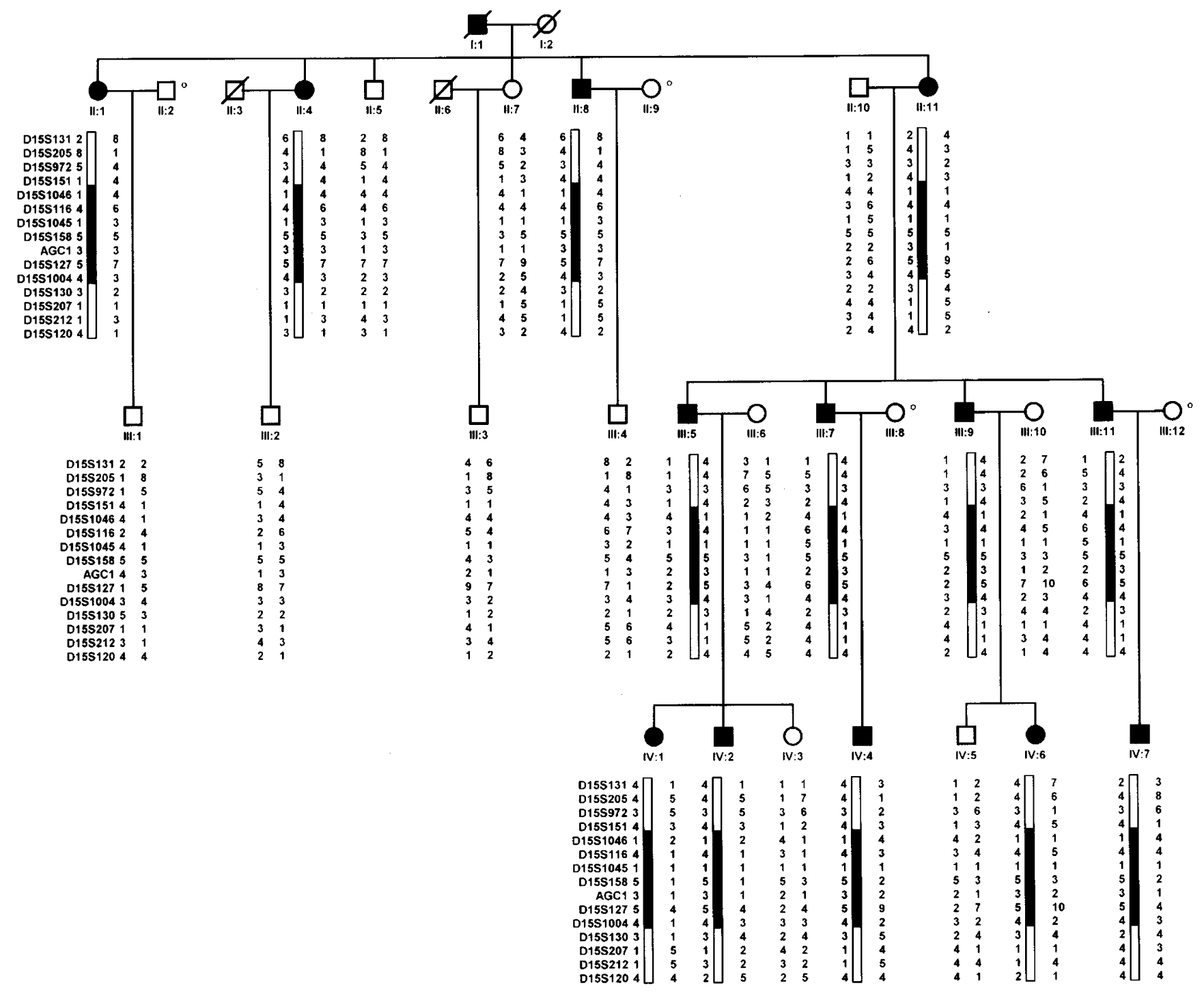

Figure 1 Four generation pedigree of the tested Italian family with non-syndromic hearing impairment. AGC1 is the tandem repeat polymorphism lying in the coding region of Aggrecan gene. Blackened circles and squares indicate member reported to be affected. $\left({ }^{\circ}\right)$ indicates examined subjects.

buffer (100 mM Tris $\mathrm{HCl} \mathrm{pH} 8.3,500 \mathrm{~mm} \mathrm{KCl}), 1.5 \mu \mathrm{l} \mathrm{MgCl}_{2}$ (25 mM), $1.5 \mu \mathrm{l}$ dNTPs mix (2.5 mM), $1 \mu \mathrm{l}$ primer mix $(5 \mu \mathrm{M})$ and $0.6 \mathrm{U}$ of AmpliTaq Gold ${ }^{\mathrm{TM}}$ (PE Applied Biosystems, Foster City, CA, USA). PCR products were analysed on a model 310 automated fluorescent DNA sequencer (PE Applied Biosystems) a four-colour detection system. One $\mu \mathrm{l}$ of PCR reaction was combined with $20 \mu$ l of formamide and $0.5 \mu \mathrm{l}$ of a fluorescent size marker (TAMRA GS-500; PE Applied Biosystems). Each sample was run for $30 \mathrm{~min}$. During electrophoresis the fluorescence detected in the laser scanning region was collected and stored using Genescan Collection software (version 3.1; PE Applied Biosystems). The fluorescent data collected during the run were analysed automatically by the Genescan Analysis program (PE Applied Biosystems) at the end of each run. Each marker was examined by the Genotyper program (version 2.0; PE Applied Biosystems) in order to analyse inheritance patterns and prepare the allele labels for export to linkage applications.

\section{Linkage analysis}

Linkage analysis was performed by the LINKAGE 5.1 computer program package. ${ }^{6}$ Two-point LOD scores between the disease gene and each marker ware calculated by means of MLINK program. The phenotype was coded as an autosomal dominant trait with a disease-allele frequency of 0.0001 segregating and penetrance was set to 0.95 for 
heterozygotes. Actually, the existence of individuals with sub-clinical signs and the variability of age at onset of postlingual deafness have prompted several authors to assume incomplete penetrance for linkage calculations. ${ }^{7-9}$ Equal recombination frequencies for males and females were assumed. The order of the markers loci and their recombination distances used for multipoint linkage analysis were based on Génethon linkage map. ${ }^{10-12}$ Multipoint analysis was performed with VITESSE computer program. ${ }^{13}$

\section{Candidate gene analysis}

A sequence analysis of the entire Aggrecan (AGC1 MIM 155760) coding region was performed. PCR primers and annealing conditions were as described by Valhmu et al. ${ }^{14}$ Amplification products were sequenced in both directions, with use of CEQ Dye terminator Cycle Sequencing Kit (Beckman Coulter, Fullerton, CA, USA) on a CEQ 2000 sequencer (Beckman Coulter). Electropherograms were analysed using CEQ 2000 DNA Analysis System 1.1 software (Beckman Coulter). Sequences were compared with those of the two transcript variants of human AGC1 (GeneBank accession number NM001135, NM013227) using Sequencher software version 4.0.5 (Beckman Coulter).

The same conditions were used to sequence the entire coding region and $177 \mathrm{bp}$ of the $3^{\prime}$ UTR of PTD014 gene (GeneBank accession number AF092135). We used primers PTD1 (corresponding to nt 11-29), PTD2 (corresponding to nt 661-680), PTD3 (corresponding to nt 328-348) and PDT4 (corresponding to nt 778-795) which amplify a 785-bp product containing the entire coding sequence (included in a single exon) plus $52 \mathrm{bp}$ of the $5^{\prime}$ UTR and $177 \mathrm{bp}$ of the $3^{\prime}$ UTR.

\section{Results}

\section{Linkage analysis}

Linkage genome wide screen was conducted in 24 individuals of the family using microsatellite markers at intervals of

Table 1 Two-point lod scores at 12 polymorphic markers on chromosome $15 q 25-26$

\begin{tabular}{lrrrrrrr}
\hline \multicolumn{7}{c}{ LOD score at $\theta=$} \\
\hline Markers & 0.00 & 0.01 & 0.03 & 0.05 & 0.10 & 0.20 & 0.30 \\
D15S205 & -2.84 & 2.92 & 3.24 & 3.30 & 3.19 & 2.59 & 1.76 \\
D15S972 & -5.47 & -0.06 & 0.44 & 0.66 & 0.88 & 0.85 & 0.56 \\
D15S151 & -3.30 & 2.37 & 2.70 & 2.79 & 2.71 & 2.21 & 1.49 \\
D15S1046 & 2.31 & 2.27 & 2.17 & 2.08 & 1.83 & 1.34 & 0.85 \\
D15S116 & 1.17 & 1.21 & 1.27 & 1.31 & 1.32 & 1.19 & 0.91 \\
D15S1045 & -0.56 & -0.47 & -0.34 & -0.23 & -0.03 & 0.16 & 0.20 \\
D15S158 & 1.17 & 1.15 & 1.10 & 1.05 & 0.92 & 0.64 & 0.36 \\
ACC1 & 3.86 & 3.79 & 3.66 & 3.53 & 3.18 & 2.42 & 1.57 \\
D15S127 & 3.98 & 3.97 & 3.93 & 3.85 & 3.59 & 2.85 & 1.92 \\
D15S1004 & 4.12 & 4.05 & 3.10 & 3.77 & 3.40 & 2.59 & 1.68 \\
D15S130 & -1.21 & 1.98 & 2.42 & 2.57 & 2.63 & 2.25 & 1.55 \\
D15S207 & -2.28 & 0.82 & 1.22 & 1.36 & 1.44 & 1.27 & 0.89 \\
\hline
\end{tabular}

$\sim 10 \mathrm{M}$, and a maximum two-point LOD score $\left(\mathrm{Z}_{\max }=4.12\right.$; $\theta=0)$ was obtained with marker D15S1004 (Table 1). Haplotype analysis disclosed key recombination events between D15S127 and D15S130 in individual IV:7, defining the telomeric boundary of the disease interval (Figure 1). The centromeric limit is determined by a crossover between D15S205 and D15S127, observed in subject II:1 (Figure 1). Seven additional markers were typed in order to confirm linkage and for fine mapping the genetic interval (Table 1) and an informative crossover with D15S151 in the subject II:1 placed DFNA30 centromeric limit to this marker (Figure 1). Therefore, the DFNA30 locus lies within the $18 \mathrm{~cm}$ region delimited by D15S151 and D15S130 markers. A multipoint analysis was also performed, using the location score method. This analysis gave a maximum LOD score of 4.34 with a most likely location for the deafness gene between D15S151 and D15S130 (Figure 2). As expected, this result is consistent with the disease location determined by the haplotype analysis.

\section{Candidate gene analysis}

In an effort to identify the DFNA30 gene, we have tested several candidates. One of the most interesting genes that have been mapped to the DFNA30 interval is aggrecan (AGC1 MIM 155760). ${ }^{14}$ This gene is an excellent candidate because mutations in the homologue mouse mutant produce hearing impairment. To investigate AGC1 as a candidate gene, we first examined the segregation of a tandem repeat polymorphism lying in the coding region. ${ }^{15}$ The polymorphism segregates through our family with four alleles and detects no recombinations with DFNA30 locus (LOD score 3.86 at $\theta=0$, Figure 1). A sequence analysis of the entire AGC1 coding region was then performed. Analysis of the AGC1 coding region in two affected family members and a control individual disclosed two sequence variants G884A and C2737A. Since both substitution alter restriction enzyme sites ( $P v u \mathrm{II}$ and $B s m \mathrm{I}$ ), we examined the corresponding RFLPs in the entire family. This analysis revealed the presence of both variants in several unaffected individuals, thus ruling out their involvement in the disease pathogenesis. The heterozygosity for these single nucleotide polymorphisms and for the tandem repeat polymorphism lying in the coding region in some hearing impaired subjects excluded the possibility of a deletion within the AGC1 gene. Altogether, these results rule out the possibility that AGC1 is the DNFA30 locus. A search of the Human Cochlear cDNA Library and EST Database (http://hearing.bwd.harvard.edu/cochlearcdnalibrary.htm) showed at least three ESTs expressed mapping within the 15q25-26 area (A001T02; SHGC-31925; SHGC15193). A subsequent BLAST search demonstrated that one of them (SHGC-31925) is actually a portion of the PTD014 gene (GeneBank accession number AF092135). Thus PTD014 can be considered a potential candidate for DFNA30, since all known mutations leading to deafness in humans occur in genes that are expressed in specialised cell of the cochlea. We 


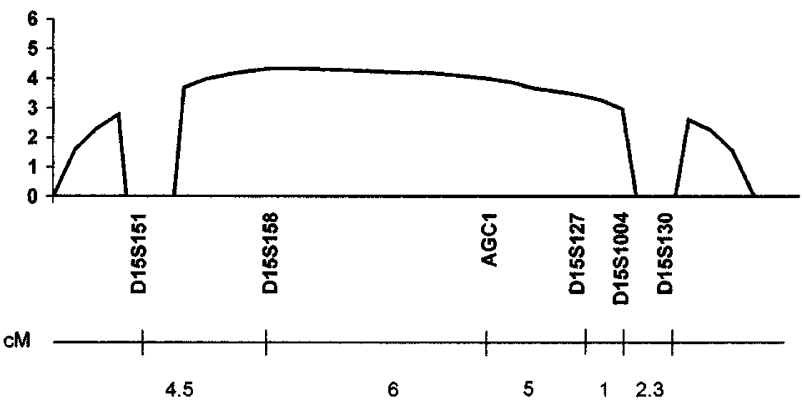

Figure 2 Multipoint LOD-score analysis of the DFNA30 locus interval. The $Y$-axis represents multipoint LOD score $\left(\log _{10}\right.$ value), and the $\mathrm{X}$-axis represents the genetic distance (in $\mathrm{CM}$ ) along the interval. Distances between markers were obtained from Genethon map.

sequenced the entire coding region and $200 \mathrm{bp}$ of the 5' UTR of PTD014 in two patients of this family, but no mutations or polymorphisms were detected. To date, no other gene mapping within the DFNA30 interval meets the requirements for a likely candidate.

\section{Discussion}

We mapped by linkage analysis the disease locus for DFNA30 to an $18 \mathrm{~cm}$ region on chromosome $15 \mathrm{q} 25-26$. The $18 \mathrm{~cm}$ disease region does not overlap with DFNB16 locus ${ }^{16}$ but partially coincides with the otosclerosis (OTS) locus. ${ }^{9}$ This suggests the intriguing hypothesis that the hearing impairment observed in our pedigree may be an allelic disease of OTS, even if there are not clinical signs of OTS in our patients. On the other hand, the possibility of two deafness-related genes lying close to each other on 15q25-q26 can not be ruled out. Instances of both phenomena have been reported in previous literature. Mutations of MYO7A can cause both deafness (inherited as a dominant or recessive trait) and Usher syndrome $1 \mathrm{~b}$, a recessive condition characterised by deafness and retinitis pigmentosa. ${ }^{17-19}$ On the other hand, two distinct connexin genes account for deafness segregating with the DFNA3 locus. ${ }^{20,21}$ So, only the isolation of OTS and DFNA30 genes is expected to elucidate the relationship between the two disorders.

Haplotype analysis demonstrated evidence of reduced penetrance (Figure 1). Individual III:1, who had inherited the at-risk haplotype, was clinically tested but no evidence was found that met criteria for affected status. It has been increasingly recognised that autosomal dominant hearing loss phenotypes may vary widely even between individuals from the same family. ${ }^{2,22}$ It has been hypothesised that other genetic factors or 'modifier genes' may influence the expression of the hearing loss phenotype. ${ }^{23}$ In particular, a modifier locus (DFNM1) has recently been identified which underlies non-penetrance of DFNB26 deafness. ${ }^{24}$ Thus,
DFNM1 and/or additional modifiers may be responsible of many well-documented cases of intrafamilial variable expressivity for deafness.

In an effort to identify the DFNA30 gene, we have tested two candidates: AGC1 and PTD014. However mutation screening of these two genes in DFNA30 patients remained negative, indicating that they are not involved in DFNA30. To date, no other gene mapping within the DFNA30 interval can be considered a candidate for the disease. On the other hand, the 18-cM disease region defined by haplotype reconstruction and multipoint analysis is still very large. Besides, recruiting additional families in linkage to the same locus seems problematic, given the great genetic heterogeneity of NSHI. In this context, a significant refinement of the disease locus may be achieved by investigating further the family genealogy and by tracing additional affected relatives.

\section{References}

1 Cohen MM, Gorlin RJ: Epidemiology, etiology and genetic patterns. In Gorlin RJ, Toriello HV, Cohen MM (eds). Hereditary hearing loss and its syndromes. Oxford: Oxford University Press, 1995. pp. 9-21.

2 Keats BJ, Berlin CI: Genomics and hearing impairment. Genome Res 1999; 9: 7-16.

3 Van Camp G, Willems PJ, Smith RJ: Nonsyndromic hearing impairment: unparalleled heterogeneity. Am J Hum Genet 1997; 60: $758-764$.

4 Steel KP, Kros CJ: A genetic approach to understanding auditory function. Nat Genet 2001; 27: 143-149.

5 Heller S, Hudspeth AJ: Two deaf mice, two deaf mice: murine candidate genes pinpoint the genetic bases of non-syndromic hearing loss in humans. Nat Med 1998; 4: 560-561.

6 Lathrop GM, Lalouel JM: Easy calculations of lod scores and genetic risks on small computers. Am J Hum Genet 1984; 36: $460-465$.

7 Manolis EN, Yandavi N, Nadol Jr JB et al: A gene for nonsyndromic autosomal dominant progressive postlingual sensorineural hearing loss maps to chromosome 14q12-13. Hum Mol Genet 1996; 5: $1047-1050$.

8 van Camp G, Coucke P, Balemans W et al: Localization of a gene for non-syndromic hearing loss (DFNA5) to chromosome 7p15. Hum Mol Genet 1995; 4: 2159 - 2163.

9 Tomek MS, Brown MR, Mani SR et al: Localization of a gene for otosclerosis to chromosome 15q25-q26. Hum Mol Genet 1998; 7: $285-290$

10 Dib C, Faure S, Fizames C et al: A comprehensive genetic map of the human genome based on 5,264 microsatellites. Nature 1996; 380: $152-154$

11 Weissenbach J, Gyapay G, Dib C et al: A second-generation linkage map of the human genome. Nature 1992; 359: 794-801.

12 Gyapay G, Morissette J, Vignal A et al: The 1993-94 Genethon human genetic linkage map. Nat Genet 1994; 7: 246-339.

13 O'Connell JR, Weeks DE: The VITESSE algorithm for rapid exact multilocus linkage analysis via genotype set-recoding and fuzzy inheritance. Nat Genet 1995; 11: 402-408.

14 Valhmu WB, Palmer GD, Rivers PA et al: Structure of the human aggrecan gene: exon-intron organization and association with the protein domains. Biochem J 1995; 309: 535 -542.

15 Doege KJ, Coulter SN, Meek LM, Maslen K, Wood JG: A humanspecific polymorphism in the coding region of the aggrecan gene. Variable number of tandem repeats produce a range of core protein sizes in the general population. J Biol Chem 1997; 272: $13974-13979$ 
16 Campbell DA, McHale DP, Brown KA et al: A new locus for nonsyndromal, autosomal recessive, sensorineural hearing loss (DFNB16) maps to human chromosome 15q21-q22. J Med Genet 1997; 34: 1015 - 1017.

17 Liu XZ, Walsh J, Mburu P et al: Mutations in the myosin VIIA gene cause non-syndromic recessive deafness. Nat Genet 1997; 16: $188-190$.

18 Liu XZ, Walsh J, Tamagawa Y et al: Autosomal dominant nonsyndromic deafness caused by a mutation in the myosin VIIA gene. Nat Genet 1997; 17: 268-269.

19 Weil D, Kussel P, Blanchard S et al: The autosomal recessive isolated deafness, DFNB2, and the Usher 1B syndrome are allelic defects of the myosin-VIIA gene. Nat Genet 1997; 16: 191-193.

20 Grifa A, Wagner CA, D'Ambrosio L et al: Mutations in GJB6 cause nonsyndromic autosomal dominant deafness at DFNA3 locus. Nat Genet 1999; 23: 16-18.
21 Kelsell DP, Dunlop J, Stevens HP et al: Connexin 26 mutations in hereditary non-syndromic sensorineural deafness. Nature 1997; 387: $80-83$.

22 Bom SJ, Kunst HP, Huygen PL, Cremers FP, Cremers CW: Nonsyndromal autosomal dominant hearing impairment: ongoing phenotypical characterization of genotypes. Br J Audiol 1999; 33: $335-348$

23 Greene CC, McMillan PM, Barker SE et al: DFNA25, a novel locus for dominant nonsyndromic hereditary hearing impairment, maps to 12q21-24. Am J Hum Genet 2001; 68: 254-260.

24 Riazuddin S, Castelein CM, Ahmed ZM et al: Dominant modifier DFNM1 suppresses recessive deafness DFNB26. Nat Genet 2000; 26: $431-434$. 